\title{
DEVELOPING MODULE FOR ENTREPRENEURSHIP- BASED TRANSLATION AND INTERPRETING SKILLS COURSE IN ENGLISH LANGUAGE TEACHER EDUCATION DEPARTMENT
}

\author{
Siyaswati \\ University of PGRI AdiBuana Surabaya \\ siyaswati@unipasby.ac.id \\ Dyah Rochmawati \\ University of PGRI AdiBuana Surabaya \\ dyahrochma@unipasby.ac.id
}

\begin{abstract}
The present study describes the development of a course module on Entrepreneurship-Based Translation and Interpretation Skills for the students of English Language Teacher Education Department. The module was inspired by empirical research findings about the knowledge base of student teachers. It was created and refined during its three-year application will be reflected upon here, including feedback collected from student evaluation sheets. In the end, the participants responded positively to the course module. The students stated that the module was interesting, relevant and valuable for their later profession. They also emphasized that they now felt more competent in the area of Translation and Interpretation Skills and entrepreneurship.
\end{abstract}

Keywords: module development, Translation and Interpretation course, entrepreneurship-based

\section{INTRODUCTION}

There has been a boom in institutional training of translators and interpreters since the mid-twentieth century and in particular since the 1980s. This also led to a survey of the way in which it could be best taught, in order to enhance the different skills acquired in one or more foreign languages and cultures, in relation to and in conjunction with the mother tongue, for the purpose of more effective communication (Liu, 2013).

One of the main aims of the present survey is to shed some light on how the teaching of translation has adapted to the changing conditions of the professional world and to the demands facing translators today. What emerged is a general trend on the part of the majority of institutions to introduce a translation training component into their curricula to satisfy not only market needs but also the growing demands within higher education for professionally oriented degrees. Much still to be done before the teaching of translation in higher education can really be said to be in line with real-world criteria and before all the institutions that have a translation component in their curricular accept the fact that training translators constitutes a serious pedagogical challenge (Liu, 2013). 
The 21 st century teaching and learning focuses on the discrete combination of 21 st century student outcomes (a blending of specific skills, content knowledge, expertise and literacies) with innovative support systems to help students master the multi-dimensional abilities required of them in the 21st century and beyond (Pacific Policy Research Center, 2010; dela Cruz, 2015).

Many higher education language departments have now begun to show greater interest in translation as a vocational tool and in the lessons to be learnt from those who earn their living from translation. Practice is now often based on the questions: "How do professional translators go about their job?" and "What does a professional translator do?" (Hervey \& Higgins, 1992).

To have a successful teaching of Translation, the best teaching approaches is the one which lead to better succeed, and help teacher to succeed in initiating the favored changes with students, furthermore, this teaching approach includes planned procedures which teacher utilizes in dealing with his students in order to make education easy and smooth. Most current teaching practices in Translation courses have been 'the teacher-blackboard-textbook relationship. Research findings have shown that there is a need to fulfill individuals' aspiration and hopes that are increasingly expand and getting larger, consequently, result in selfeducation programs and utilize the technology and clarify its role in the teaching system which provides the different presentation opportunities especially regarding the texts. Therefore it is the need the need emerged for the teaching approaches that are far from conventional approaches of school and the teachers, are more suitable for the modern age of information technology and the module approach is considered the modern approach of development. It is methodological way in thinking and organized way in working handling all the factors included in the teaching process. It is "a small teaching unit based on strategy of the selflearning and individualization of the education, the unit contain specific objectives, experiences, and certain teaching activities carried out in sequence and logical completion to help the learner to achieve the goals and develop the sufficiency according to the agreed levels specified previously according to the speed of self-learning. "it is a small teaching unit based on strategy of the selflearning and individualization of the education, the unit contain specific objectives, experiences, and certain teaching activities carried out in sequence and logical completion to help the learner to achieve the goals and develop the sufficiency according to the agreed levels specified previously according to the speed of self-learning" (Alelaimat \& Ghoneem, 2012, p. 44).

A learning module is one of study material that facilitates the teaching and learning processes, stimulate learner's mind in a way that helps in being attentive to the instructions process, focus, comprehension and recalling for the purpose of enhance and increase the process efficiency along with thinking development. This kind of self-instruction or individualization of instruction addresses the individual differences of the learners believing that this learner is unique and special, and teaching is individual process. This can reduce the dependency on the teacher and give attention to learner who becomes the center of activities which aim at attaining the objectives of the teaching process for the learner (Alelaimat \& Ghoneem, 2012).

The teaching of the Translation and Interpretation Skills course in the English Language Department was the conventional method which was mainly 
depending on the one source who was the teacher. It did not comply with the technology development. Due to the importance of developing the methods of teaching the course and paying attention to it as part of means of executing the curriculum and achieving its goals by carrying its different content and activities and moving from the conventional method to modern concept of applying the method of modern and diversity teaching method, such as the modules method and strategy.

The translation and interpretation skills is one of the competences that a graduate of the English Language Education Department must have. It can create a prospective opportunity for him in addition to becoming a teacher of English, in particular if he wants to be self-employed as a translator or interpreter. In response to this, entrepreneurship education is inevitable. Entrepreneurship education equips individuals with "the ability to recognize commercial opportunities, selfesteem, knowledge and skills to act on them. It includes instruction in opportunity recognition, commercializing a concept, managing resources, and initiating a business venture. Entrepreneurs or the move towards self- employment is, and will continue to become, an increasingly important element of economic growth and development" (Grecu \& Denes, 2017, p. 1). To integrate the entrepreneurship education into the Translation and Interpretation Skills course is intended to promote students' entrepreneurial mind-set and encourage self-employment.

\section{Problem}

In response to a need identified by the needs analysis, a 12-week learning module was developed intended mainly for the fourth-year students who need a beginning knowledge of translation and interpretation studies. This module aims to support students' understanding of the translation studies by providing them with opportunities to independently investigate through both research and experimentation.

\section{Purpose of writing}

The present article documents the experience and lessons from developing an integrated entrepreneurship-based Translation and Interpretation Skills course module designed for the fourth-year students of the English Language Department.

\section{METHOD}

This study aimed to develop a complete practical comprehensive module to improve students' entrepreneurial skills, particularly to their managerial aspects in translation industrial context. The study was conducted over the students at the English Language Education Department of University of PGRI Adi Buana Surabaya taking the Translation and Interpretation Skills course in the fourth year of their study. A total of 96 student teachers participated in the course. The reliability and consistency of the module were obtained through a panel of experts in teaching methods. The research and development approach with the design based research (Elly and Levy, 2010) was employed as the technique of this present study. For the data collection and analysis through design-based approach, several procedures were conducted, which involved (1) problem identification, (2) 
objectives framing, (3) product design and development, (4) product examination and test, (5) result evaluation, and (6) result communicating. This integrated module involved three major parties; the students, the course manager, and the lecturers.

During the sixteen-week course, the course modules were designed to cover all aspects involved in writing a proposal for a business in the translation industry as an entrepreneurial practice. The course was organized with lesson materials broken down into four to five brief lesson modules covered on a weekly basis and designed to take approximately an hour and a half per module. The learning materials began with an introduction to the purpose of proposals and a discussion of when writing a full proposal is required. Topics over the following weeks addressed the specific components of a proposal and the suggested order in which proposals should be developed. During the latter half of the course, the module addressed topics such as the proposal's logical framework, budgets and the proposal components that are prepared at the end of the development process, such as the background section, summary and proposal cover letters.. The course was organized with lesson materials broken down into four to five brief lesson modules covered on a weekly basis and designed to take approximately half an hour per module. The learning materials began with an introduction to the purpose of proposals and a discussion of when writing a full proposal is required. The topics over the following weeks addressed the specific components of a proposal and the suggested order in which proposals should be developed. During the latter half of the course, modules addressed topics such as the proposal's logical framework, budgets and the proposal components that are prepared at the end of the development process, such as the background section, summary and proposal cover letters.

The module took the following design as suggested by Alelaimat \& Ghoneem (2012):

(1) The title of the module representing the main idea of the module taking into consideration,

(2) The introduction of the module motivating and encouraging the students to read and providing a general idea about the subject and what to achieve,

(3) The learning goals clarifying the expected behavior to be achieved after finishing the study of the module,

(4) The pre-test and the key answers determining the level of the student according to the behavior objectives set previously (the pre-test is used alongside the post-test to determine the range of success of the student to pass to the next module after checking his answers with the key answer and the corresponding marks accompanied with each module, in case of failure, has to keep studying the module,

(5) The organization of the content of the module:

The content is divided into clear secondary factors and ideas which help the student to understand them easily and presented in many forms with many references to be suitable with the capabilities and tendencies of the student. It is adjusted in many logical ways according to the nature of the material and the characteristic of the students, whom the module is designed for,

(6) The activities and teaching utilities: 
Each module consist of group of diversity of teaching practices enabling the student to choose from what suits him from application and referral activities to achieve the required goals with the support of the variety of the teaching resources,

(7) The chosen recourses and references:

In the last pages of the module there will be annex for the reading of the printed and picture material of the book and the reference in the different fields in addition to the list of the references and resources for the student for further expansion to enrich his information about the subject,

(8) The post-test:

It is another form of the pre-test or has some new items related to the behavior objective of the subject which is written previously. In case of passing the student moves to the next module, if failed the student has to study the same subject again until he passes.

The characteristics of the teaching and learning process as previously reflected in the module design are:

(1) The student has his own self learning which allows time for discussion study anytime anywhere,

(2) The individual and environmental differences among the students are considered,

(3) The positive and participation of the student is encouraged,

(9) Learning with purpose in the life of the students is addressed,

(10) There is connection and integration among the subjects,

(11) There is a group interaction among the students,

(12) The teacher is the leader, guide, developer, and the encourager.

\section{FINDINGS AND DISCUSSION}

\section{Problem identification}

This problem identification stage basically assessed the needs of the students. It was intended to discover the four categories of information about their potential learners in particular that the researchers use to tailor the learning materials. They included (1) demographics, (2) motivation, (3) learning factors (study skills); and, (4) subject background (Freeman, 2004 in Babu, 2014).

In regard to this needs, it argued that a simple and practical entrepreneurial module is urgently needed. The module should cover some basic characteristics corresponding to the students' expectation, be practical and easy to learn, present in simple sentences, provide less yet comprehensive theories along with various exercises, and contain means for entrepreneurial mental building and practical business management. In addition, the various types of group learning activities include: small-group discussions, debates, demonstration and practice, situational analysis, case studies, learner presentations, and role-plays.

\section{Objectives framing}

The framing of the objectives and scope on the module design and content was necessary to make an integrated module effective before it was verified onto 
the related courses. In framing the objectives, it needed to scope the content which corresponded to the outcome of problem identification. Thus, the objectives should include the design and content of the modules. The design displayed an interesting layout, and the materials are presented in brief context attributed with some figures in order to encourage students' curiosity. In addition, the content contained work ethic, creativity for business development, business initiating, business management, and marketing development (Crea, 2010).

\section{Product design and development}

On the basis of identifying the problem, verification on the data collected resulted in: 1) the composition of materials covers the spirit in running a business, fostering creativity, business cooperation, and managing the business, 2) practical and applicable theories attributed with examples and tasks, 3) autonomous learning-based design. Those all pointed to both students' and instructors' expectations, which wanted to discover an appropriate set of effective evaluation (Henry, 2004).

The research and development with Design-Based Research approach resulted in 1) The implementation of each phase required sufficient time for validation, 2). The researcher of this study acted as an informative assembler and facilitator drafting the module that corresponded to the user needs, being proactive and communicative with the users, 3). A sense of belonging and good cooperation between the researcher and the users were found exist in the process of product research and development to obtain effective materials. The design-based research approach was applied in several stages which brought different result as well. Identifying problems resulted in students' educational and economic background, and parents' job. In regard to content drafting, it was necessary to consider several aspects including 1) who the students are, (2) how their attitudes and entrepreneurial traits are, 3) the level of readiness, 4) students' motivation and innate, and 5) various theories and generalizations of translation practices including translational text analyses, translations with commentaries and translation criticism. Those aspects eventually could contribute to an effective and interesting learning. The courses participants are mostly fresh graduate of senior high school $(80 \%)$. they were capable to receive and absorb knowledge more quickly rather than other participants from different educational background as they were more confident and actively engaged in training. The curriculum applied by the courses related to entrepreneurship is naturally practical. These entrepreneurial materials include work ethic, business initiation and material procurements, and business management and communication. The strategy of entrepreneurship learning referred to be integrative between theory and practice and simultaneously conveyed during the course (Omar, et al; 2010). The success of entrepreneurship did not always deal with the financial (capital) factor but also from non-financial factor, prominently, high personal entrepreneurial traits such as skills, innovations, dexterity to run a business as well as its problems (Malaya, 2006; Ahn, et al, 2008; Randolph, 2013).

In module drafting, the structure of the course developed in this project was adapted from the model proposed by Sudarwati (2018) and encompassed different topics. The course module had a duration of twelve weeks with one ninety minute session per week. It was set in four chapters that consisted of building 
entrepreneurship passion, managing the business, developing practice and integrating business plan, and various theories and generalizations of translation and interpretation practices. The draft of the module was classified into three sections as follow. 1) The Initial. It described the correlation between each chapter along with its characteristics, provided the prerequisite of using the module, and verified 4 major objectives for business development. Also, it provided a brief explanation and evaluation to do the given exercises. 2) The Main. It consisted of four chapters respectively talking about entrepreneurship skills, business skills, how to make an integrated business plan, and translation and interpretation skills. Specifically, each chapter was different in: a) title -(1) Chapter 1: initiating entrepreneurship traits, (2) Chapter 2: managing the business, and (3) Chapter 3: business planning, and (4) Chapter 4: translation and interpretation in practice; b) Goals and objectives comprehensively described within each chapter; and c) topics -(1) Chapter 1 consisted of 5 topics including the concept of entrepreneurship, entrepreneur as the leader, decision making and risk taking, creativity, and negotiating skill; (2) Chapter 2 consisted of 6 topics including determining and planning to produce a new product and market it to the customers, marketing and sales planning, counting break event points, financial and cash flow statements, human resource developments, and annual business planning; Chapter 3 consisted of 1 topic discussing about how to draft a business plan, and Chapter 4 consisted of 4 topics addressing various theories of translating and interpreting, and translation and interpretation practices.3) The Final. It provided 1) closing statements containing general guidance on what students should do next using integrated entrepreneurial module, and 2) bibliography, providing theoretical references and sources of the module.

\section{Product examination and test}

In module trial, it showed a significant improvement of students' skills in management aspects and entrepreneurial practice as they used the module. The validation found that it successfully met the requirement of an autonomous learning module. This is consistent with Ismail (2010) that the responses of female students are more positive than male students' toward the entrepreneurship module considering the time flexibility, working hour and managing house chores. Thus, learning with module is a kind of self-instruction individual learning model. Finally, evaluating the effectiveness of module was measured by some quantitative measurements. The results of each trial showed that the module is found effective to be applied as an autonomous learning module. It found that $80 \%$ of the students were able to implement all the managerial aspects in business. In addition, its design mainly consisted of the initial section including title, table of contents, information maps, general purpose and evaluation guide. The main section included the topic title, learning objectives, activities, materials, evaluation, and the final section provided the module with key answers and assessment criteria.

\section{Result evaluation}

Some findings were resulted from product research and development. Developing an entrepreneurship module for courses had classified into 1) Revising modules based on students and courses manager's needs and 
expectations, 2) The content of the module should reflect the students' needs to build their personal entrepreneurial traits. 3) Validation and revision for module was through some sets of validation test; discussion among students, instructors, and collaborator; despite a quantitative measurement to verify its effectiveness. Besides its benefits toward the students, this module is also beneficial as 1) an effective media to provide a personal guide for student personally; 2) means for effective remedial as it corresponded to student learning outcomes; 3). Applicable media for anyone and anytime, played as the facilitator assistance; 4) means to make the professional task better, making students more active through selflearning; 5) an effective reflection of learning.

It found that $80 \%$ of the students were able to understand the materials contained in the integrated entrepreneurial module. It indicated that the module was effective as a learning media. Hence, it was considered appropriate and effective to use.

However, this module had some limitations, such as 1) it was less instruction, making this suitable for classroom-based learning or outdoor-group activity, noted that the assumption of students' ability to learn and complete individual tasks entirely could not be entrusted; 2) a single approach made the activity monotonous and boring, and thus, making students more introvert and resulted in lower achievements; 3) Irresponsible independency, making students not interested to do the tasks (these trait belonged to some students already); 4) learning process still needed some supporting facilities like media and adequate learning resources; 5) the module was not equipped with media such as audio or video which might help students to be more active acquiring relevant sources; and 6) It was relatively more expensive than the lecturing method. After having data collection and module revision, it suggested that this module had some sections following the model suggested by Sudarwati (2018). At the first section, it was entitled "Integrated Entrepreneurship Module for Entrepreneurial Candidates", consisting of title, preface, table of contents and introduction that described background, module user prerequisites, general purpose of the module, module usage and ability evaluation as well. At the second section, it consisted of three chapters including Chapter I "Entrepreneurship skills", Chapter 2 "Business skills", and Chapter 3 "Practice Preparing an Integrated Business Plan". Chapter 1 contained five topics including the concept of entrepreneurial characteristics, an entrepreneur as a leader, making decision and taking risk, creativity, and negotiation skills. Chapter 2 contained six topics which included defining new products to production planning, marketing and sales plans, break even points, financial reporting, human resource management and business planning. Chapter 3 contained one topic referring to the practice of developing a business plan (Faria, 2009). The design structure of each topic described the learning objectives, learning activities, materials, topic summary, answer keys, assessment criteria and bibliography. The final section contained a concluding remark Additionally, this module was earmarked for: 1) course managers who highly recommended to periodically review the material with the applied entrepreneurship curriculum in accordance to the science and business technology; 2) course instructors for mastering the content of materials in order to guide the learners individually (Likoko: 2013); and 3) students for learning the theory and practicing their entrepreneurship skills. Any further researches are necessary to develop 
entrepreneurship training module with electronic media using audio-visual display for people living in digital era like nowadays. Overall, since entrepreneurship courses provide informal education and are aimed for adult learners, the use of such module is vital for their autonomously flexible learning.

\section{Result communicating}

From the submitted learner evaluations of the module (50\% of registered learners completed the post-course evaluation and sent in their feedback), overall satisfaction with the module was good, $-74 \%$ of respondents ranked the course as good or excellent and the remaining respondents ranked the course as average $(26 \%)$. Furthermore, the vast majority of respondents $(89 \%)$ further indicated that the module was relevant and of use to them.

As the result, this research finally produced an integrated module containing 3 chapters and 12 topics. Chapter 1 described on how to initiate entrepreneurial passion and consisted of 5 complete topics. Chapter 2 described on how to manage and run a business and it contained 6 topics. Chapter 3 described on how to implement a business plan and it consisted of 1 topic only.

With this module, $78 \%$ students were found successful understanding the given materials and implementing the management aspects in their entrepreneurial practice. The feedback from the students indicated a high level of student satisfaction with the course materials. The students' feedback included (1) reducing the amount of content, (2) clarifying the unit objectives, (3) adding more summaries, (4) providing a better description of the unit, (5) updating the content, (6) increasing the amount of instructions, (7) improving unit organization, (8) adding more multimedia, and (9) adding more activities. These feedbacks provided the researchers with some clear guidance on what kind of improvements were needed.

These findings are consistent with the results of the study by Burmeister and Eilks (2013) brought about results indicating that the contents of the module developed proved valuable for offering future teachers ideas and pedagogies. The findings of the study by Haque \& K. Alagarsamy (2018) revealing that the course module plays a significant role in the undergraduate students' perception of the subject matter, better prepared students, enhanced presentation skills, and group experience. These results are also supported by Sudarwati's study (2018) shown that the module she developed proved to facilitate the students' successful learning outcomes.

\section{CONCLUSION}

To conclude, the use of this integrated module resulted in a variety of positive outcomes and was significant to improve students' ability with cognitive strategy. It was capable to make the learning process more active and sustainable. (Akpomi, 2009). It was to enhance the students' learning experience and prepare them better for their future working environment.

All in all, successful learning is a mutual process between learner and teacher towards achieving the objectives of the education. According to the module the learner is a self-learner as he is the center of the teaching process, and can find within the module the necessary resources of information that can support his learning, so he chooses what is suitable, the learner decides when he 
will starts and where to begin. He can find in the module what supports his response, encourages his motivation, immediate modification of his response, thus the learner is free and positive.

Any further researches are needed to develop entrepreneurship learning module integrated into some other courses Overall, the use of such module is necessary for their autonomously flexible learning.

\section{REFERENCES}

Akpomi, M. E. (2009). Entrepreneurship Education (EE) For All Student in Higher Education Institution (HEIs) in Negeria: A Means to Sustainable Development. Journal of Sustainable Development in Africa, 11(1), 163173.

Alelaimat, A. R., and Ghoneem, K. A.A., (2012). The Effect of Educational Modules Strategy on the Direct and Postponed Study's Achievement of Seventh Primary Grade Students in Science, in Comparison with the Conventional Approach. Higher Education Studies. 2 (2), pp. 40-61.

Babu, S. C. (2014). E-Learning and Development: Lessons from MultiDisciplinary Capacity Strengthening. Journal of Learning for Development, 1 (3).

Burmeister, M. and Eilks, I. (2013). Using Participatory Action Research to Develop a Course Module on Education for Sustainable Development in Pre-Service Chemistry Teacher Education. C E P S Journal, 3 (1), pp. 59-70.

Dela Cruz, J. P. C. (2015). Development of an Experimental Science Module to Improve Middle School Students' Integrated Science Process Skills. Paper Presented at the DLSU Research Congress 2015 De La Salle University, Manila, Philippines March 2-4, 2015.

Freeman, R. (2004). Planning and implementing open and distance learning systems: A Handbook for Decision Making. Vancouver, Canada: Commonwealth of Learning.

Grecu, V. and Denes, C. (2017). Benefits of entrepreneurship education and training for engineering students. MATEC Web of Conferences 121, DOI: 10.1051/matecconf/2017121 MSE 2017.

Haque, W.\& K. Alagarsamy. (2018). Effectiveness of Research Modules in Undergraduate Curriculum. from https://www.cs.ubc.ca/wccce/Program03/papers/Waqar.pdf.

Hervey, S., and Higgins, I. (1992). Thinking Translation. Routledge.

Pacific Policy Research Center (2010). 21st Century Skills for Students and Teachers. Honolulu: Kamehameha Schools, Research \& Evaluation Division.

Sudarwati, N. (2018). Compiling Integrated Entrepreneurship Module by Using Design-Based Research Approach to Improve Students' Entrepreneurial Skill. Journal of Sustainable Development, 11 (1), pp. 83-90.

Liu, J. (2013). Translators Training: Teaching Programs, Curricula, Practices. Journal of Language Teaching and Research, 4 (1), pp. 127-132. 